\title{
Development of an ejector cooling system with thermal pumping effect
}

\author{
B.J. Huang*, S.S. Hu, S.H. Lee \\ Department of Mechanical Engineering, National Taiwan University, Taipei, Taiwan, ROC
}

Received 30 May 2005; received in revised form 16 August 2005; accepted 22 August 2005

Available online 28 October 2005

\begin{abstract}
This paper presents a feasibility study of an ejector cooling system (ECS) that utilizes a multi-function generator (MFG) to eliminate the mechanical pump. The MFG serves as both a pump and a vapor generator. The MFG is designed based on the pressure equilibration between high and low pressures through heating and cooling process. In this design, an ECS that contains no moving components and is entirely powered by heat can be practicable. A prototype using refrigerant R141b as working fluid was constructed and tested in the present study. The experimental results showed that the system coefficient of performance $\left(\mathrm{COP}_{\mathrm{o}}\right)$ was 0.218 and the cooling capacity was $0.786 \mathrm{~kW}$ at generating temperature $\left(T_{\mathrm{G}}\right) 90^{\circ} \mathrm{C}$, condensing temperature $\left(T_{\mathrm{C}}\right)$ $32.4^{\circ} \mathrm{C}$ and evaporating temperature $\left(T_{\mathrm{E}}\right) 8.2^{\circ} \mathrm{C}$. While taking into account the extra heat needed for the MFG operation, the total coefficient of performance $\left(\mathrm{COP}_{\mathrm{t}}\right)$ is 0.185 . It is shown that a continuous operation for the generation of cooling effect in an ECS with MFG can be achieved. This cooling machine can be very reliable since there is no moving part.
\end{abstract}

(C) 2005 Elsevier Ltd and IIR. All rights reserved.

Keywords: Refrigeration; Ejector system; R-141b; Generator; Vapour; COP

\section{Dèveloppement d'un système de refroidissement à jecteur à effet de pompage thermique}

Mots clés: Froid ; Système à éjecteur ; R-141b ; Générateur ; Vapeur ; COP

\footnotetext{
Abbreviations $\mathrm{COP}$, coefficient of performance; $\mathrm{COP}_{\mathrm{o}}$, system $\mathrm{COP}$ at vapor discharge phase, in Eq. (1); $\mathrm{COP}_{\mathrm{t}}$, total system COP defined in Eq. (2); ECS, ejector cooling system; HDP, heat-driven pump; MFG, multi-function generator; ECS/MFG, ejector cooling system utilizing a multi-function generator.

* Corresponding author. Tel.: +88622362 4790; fax: +8862 23640549.

E-mail address: bjhuang@seed.net.tw (B.J. Huang).
}

\section{Introduction}

Conventional cooling systems utilize Freon compressors that are driven by electricity. However, the wide-spread application of cooling, and air-conditioning systems in summer causes a serious electric peak load problem and electrical power generation causes environmental impact as well. There are abundant of thermal energy types in the world, such as solar thermal, geothermal, various wasted heats, biomass energy, etc. Scientists are looking for a suitable cooling technology that can be powered directly by thermal energy for several decades. 


\begin{tabular}{|c|c|c|c|}
\hline \multicolumn{4}{|c|}{ Nomenclature } \\
\hline$t$ & time $(\mathrm{s})$ & $t_{\mathrm{dp}}$ & total operation time of the depressurizing and \\
\hline$Q_{\mathrm{C}}$ & rejected heat rate $(\mathrm{kJ})$ & & liquid intake phase (s) \\
\hline$Q_{\mathrm{E}}$ & cooling capacity $(\mathrm{kJ})$ & & \\
\hline$Q_{\mathrm{G}}$ & input heat $(\mathrm{kJ})$ & $\mathrm{C}$ & condenser \\
\hline$Q_{\mathrm{h}}$ & input heat of the pressurizing phase $(\mathrm{kJ})$ & $\mathrm{E}$ & evaporator \\
\hline$T$ & temperature $\left({ }^{\circ} \mathrm{C}\right)$ & $\mathrm{G}$ & generator in the ECS (the inlet port of the \\
\hline$P$ & pressure $(\mathrm{kPa})$ & & ejector in the ECS/MFG) \\
\hline$t_{\mathrm{p}}$ & operating time of the pressurizing phase (s) & & \\
\hline$t_{\mathrm{v}}$ & operating time of the vapor discharge phase (s) & & \\
\hline
\end{tabular}

Ejector cooling technology looks very promising for this need. The performance of ejector cooling system (ECS) has been improved greatly for the last decade through an extensive research. Huang et al. [1,2] showed that the COP of an ECS, with a proper design, can reach as high as 0.54 at generator temperature $84^{\circ} \mathrm{C}$, condensing temperature $28^{\circ} \mathrm{C}$, and evaporating temperature $8^{\circ} \mathrm{C}$.

The conventional ECS (Fig. 1) uses an ejector (a fluid compressor) to replace the conventional mechanical compressor in the Rankine refrigeration cycle. The only moving part in the system is the circulation pump of the working fluid from the condenser to the generator. However, in practical application, the mechanical pump used in an ECS is expensive and easy to break down since the pump material may not be compatible with the working fluid. This is one of the reasons that hinder the dissemination of the ECS, especially for small cooling unit. The development of a pump-less ECS is thus quite important.

Nguyen et al. [3] developed a pump-less ECS using a barometric siphon for pumping the working fluid. The condenser of the ECS was raised up to a high-enough level from the ground to induce a sufficient gravitational force for returning the working fluid back to the generator. This ECS

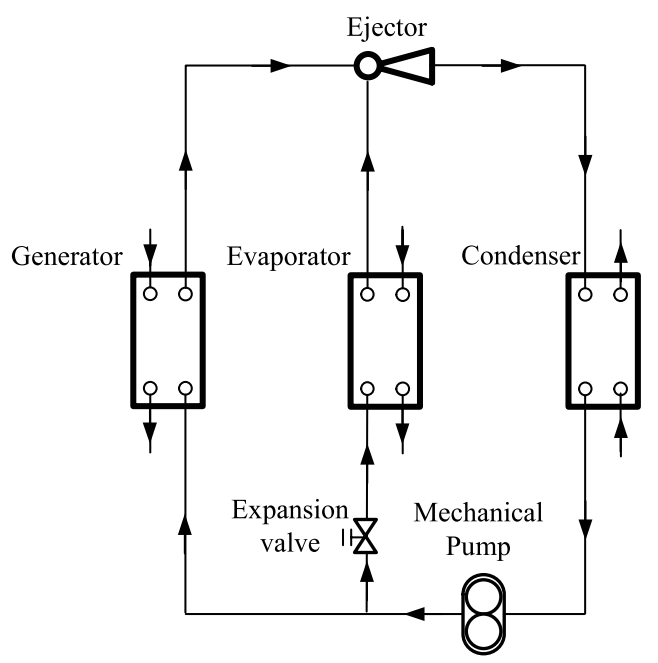

Fig. 1. Schematic diagram of ejector cooling system (ECS). used water as the working fluid and had a cooling capacity $7 \mathrm{~kW}$. The measured COP was 0.32 at generator temperature $76.7^{\circ} \mathrm{C}$, condensing temperature $26.7^{\circ} \mathrm{C}$ and evaporating temperature $1.5^{\circ} \mathrm{C}$. In this ECS, the gravity head acting as a pump was used to transfer the liquid from the low-pressure side, the condenser, to the high-pressure side, the generator. Nguyen et al. [3] presented an interesting result and showed one possible design for the ECS. Nevertheless, the necessary vertical height is as high as $7 \mathrm{~m}$ and some reliability problems, such as leaking problem, still need to be clarified.

Many investigations on the heat-driven pump (HDP) for replacing the conventional mechanical pump in various applications are reported. Sumathy [4] gave a literature survey on solar thermal pump for water. Most designs used heat to vaporize the working fluid to push the liquid contained in a closed tank to a higher elevation. Some designs were based on the principle of liquid piston engine. Extensive studies related to the HDP were carried out by many researchers [5-17]. The HDP requires no moving parts and almost no electricity for operation. The efficiency of a HDP is low in the order of $0.1 \%$ [9]. However, it may be still feasible in replacing the circulating pump of an ECS since the heat input such a kind of HDP can be re-utilized through preheating the return liquid from the vapor generator. If the required pumping power in an ECS is very low, the efficiency loss in such kinds of HDP can be negligible.

The direct use of an aforementioned HDP in an ECS is still questionable since some specially-designed parts are required for the HDP to generate work to drive the liquid. Instead, we combine the concept of HDP with the design of an ECS to come up with a new ejector cooling system without a mechanical pump. This new ejector cooling system (ECS) uses a multi-function generator (MFG) that acts as a generator for vapor generation and as a feed pump for liquid returning to the generator. The present investigation was conducted to experimentally study the feasibility of the novel ECS/MFG.

\section{Description of ejector cooling system with multi-function generator}

The schematic diagram of the ejector cooling system with multi-function generator (ECS/MFG) is shown in Fig. 2. There 
are two generators in the ECS/MFG. Each generator consists of a vapor generator (boiler) and an evacuation chamber. The vapor generator is a heat exchanger like a conventional boiler for heating the liquid in order to pressurize the whole generator and to generate vapor. The evacuation chamber is composed of a cooling jacket and a liquid holding tank. Cooling jacket provides a cooling effect to depressurize the whole generator in order to intake the liquid from condenser.

The two generators operate interchangeably through the control of two switching valves (VA and VB) and four check valves. The operation of each generator can be divided into four phases: namely, pressurizing, vapor discharge, depressurizing, and liquid intake. While generator $\mathrm{A}$ is operating at depressurizing, liquid intake and pressurizing phases, generator B is operating at a vapor discharge phase. The cooling effect of the ejector is generated at vapor discharge phase.

At pressurizing phase, the vapor generator is heated with the solenoid valve (switching valve) closed. The pressure in the whole generator increases up to a level that is required to drive the ejector. The switching valve is then opened to discharge vapor to the ejector and the generator enters into vapor discharge phase while the ejector is activated and cooling effect is produced. The vapor discharge phase will end when the generator pressure starts to drop to a level that cannot effectively drive the ejector. This will happen when the generator is almost empty. The generator then enters into the depressurizing phase with the switching valve closed and the evacuation chamber is cooled. The pressure continues to decrease to a level that is low enough to induce the liquid return from the condenser. The generator then enters into the liquid intake phase with the switching valve closed and the evacuation chamber is still cooled. This completes a cycle for the generator. The operation of the two generators is shown in Fig. 3 for the four operating phases and Fig. 4 for the pressure variation.

According to the principle of each phase mentioned above, we can see that one generator can only produce a half-cycle cooling effect. Therefore, two generators need to be coupled together to generate continuous cooling effect as illustrated in the Fig. 4. The two switching valves should be suitably manipulated to synchronize between the two generators. In such an ECS/MFG, the key issue in the design is the control of total time period of pressurizing, de-pressurizing and liquid intake phase. It must be less than or equal to the vapor discharge time. Therefore, the thermal response of the MFG device is important. In the present study, we designed and built a prototype of ECS/MFG with one MFG to firstly study the feasibility of the new design concept.

\section{Experimental design of an ECS/MFG}

\subsection{Prototype design}

A prototype following the process of Fig. 2 but only with one generator was designed and constructed to study the feasibility of the ECS/MFG. Fig. 5 schematically depicts the experimental setup. R141b was selected as a working fluid,

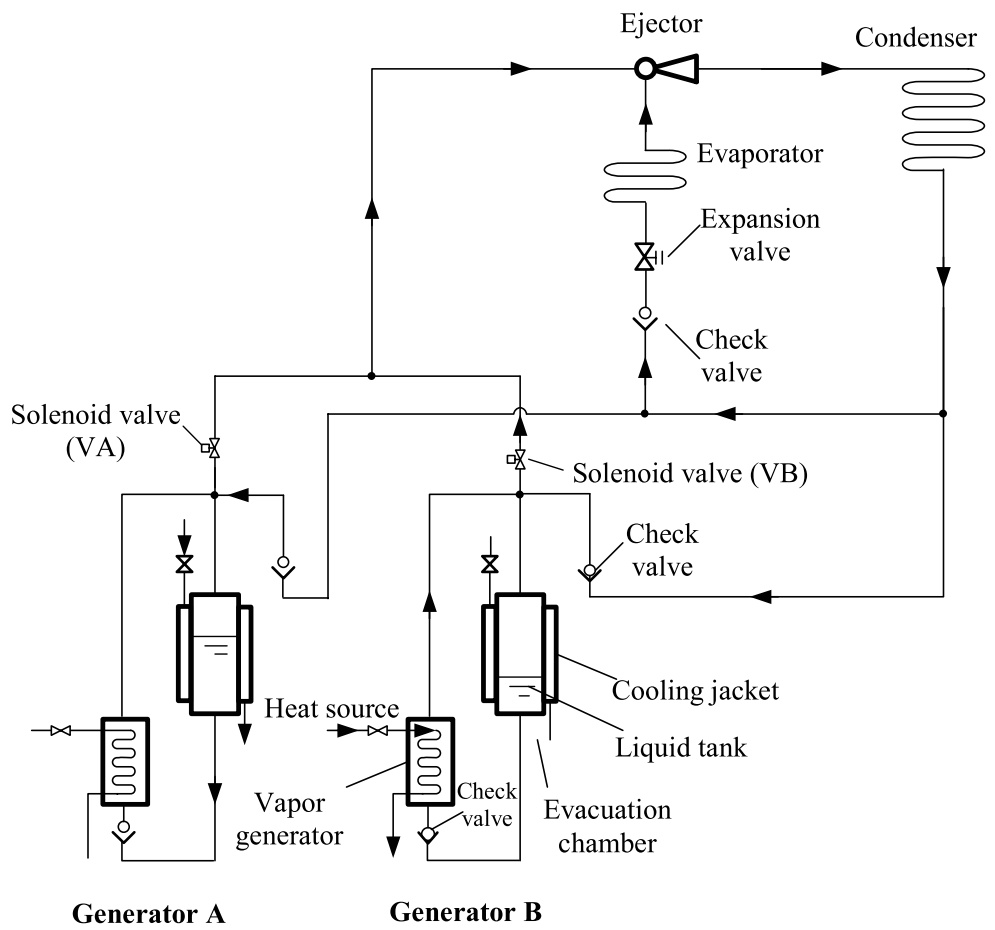

Fig. 2. Flow diagram of ejector cooling system with multi-function generator (ECS/MFG). 

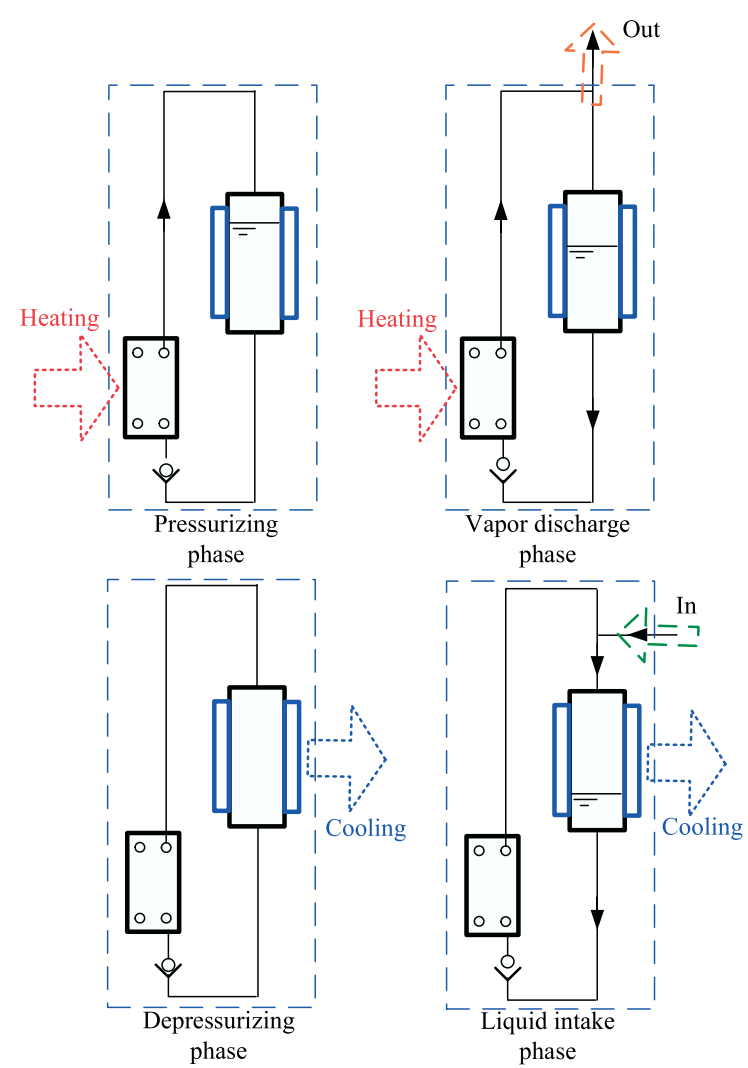

Fig. 3. Working principle of MFG.

and the design conditions are listed in Table 1 . The ejector cooling system of this ECS/MFG, principally based on the Huang's experiment $[1,2]$, is composed of an ejector, a condenser, an evaporator, a precooler, an expansion valve, and a receiver. The design specifications are listed in Table 2. Nozzle A and constant-area section $\mathrm{G}$ were selected for the ejector combination $[1,2]$ because they can be operated at a higher critical condensing temperature $\left(36.7^{\circ} \mathrm{C}\right)$. The precooler in the suction line of the ejector was used to prevent the entrained flow from condensation in mixing process inside the ejector to have a better ejector performance. For accumulating the condensing liquid from the condenser, a liquid receiver was installed beneath the condenser. The volume of the receiver was equal to the liquid tank of the MFG. The suction head for returning liquid from the liquid receiver to the liquid tank of the MFG was $63 \mathrm{~cm}$, and the total height of the prototype is about $180 \mathrm{~cm}$.

The MFG was composed of a liquid tank with a cooling jacket, one vapor generator for vapor generation and two check valves for providing one-way flow. The size of the liquid tank was carefully designed in order to reduce the thermal mass and the pressure tolerance. The specifications are listed in Table 3.

The vapor generator of the MFG was heated with steam generated by a $5-\mathrm{kW}$ electrical steam generator. All the cooling process of the MFG and the condenser was provided using the city tap water cooling system.

\subsection{Instrument setup}

Fifteen T-type thermocouples with an uncertainty of $\pm 0.7^{\circ} \mathrm{C}$ were mounted on the system. Five pressure transducers (Tecsis 3296 series) within $\pm 1 \%$ uncertainty were used. Three transducers ranging -1 to 9 bar were installed in the outlet and inlet ports of the vapor generator of MFG and inlet of the ejector. Two transducers ranging -1 to 4 bar were installed in the inlet ports of the condenser and the evaporator. A hybrid recorder (YOKOGAWA DR130)

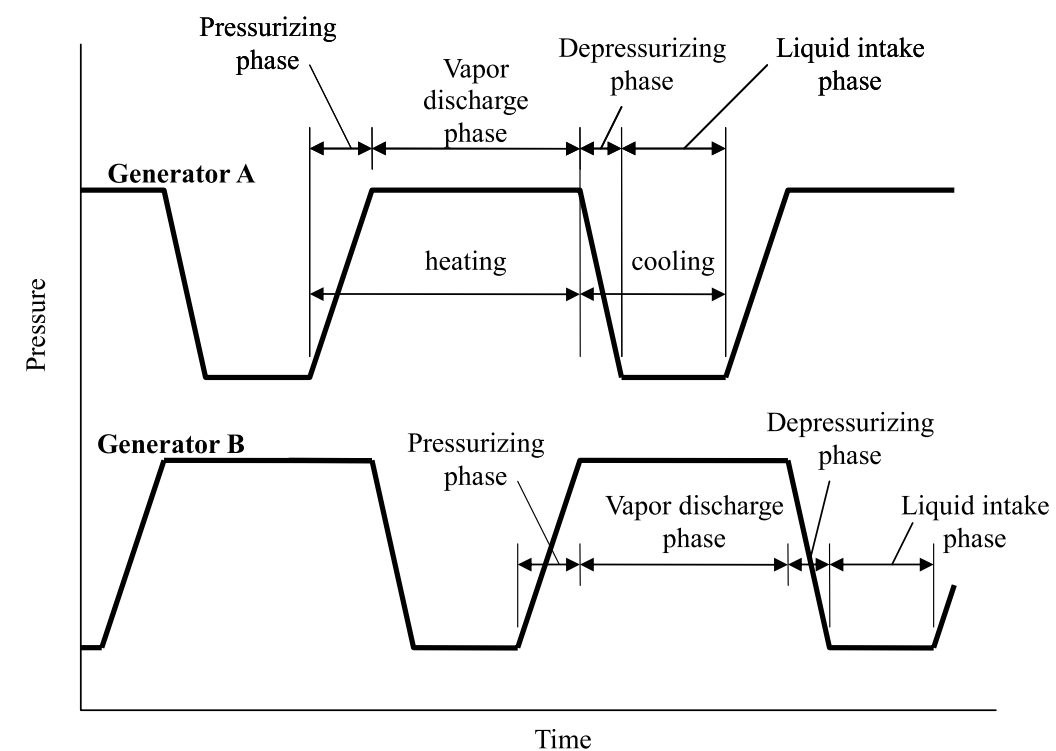

Fig. 4. Pressure variation of two generators. 


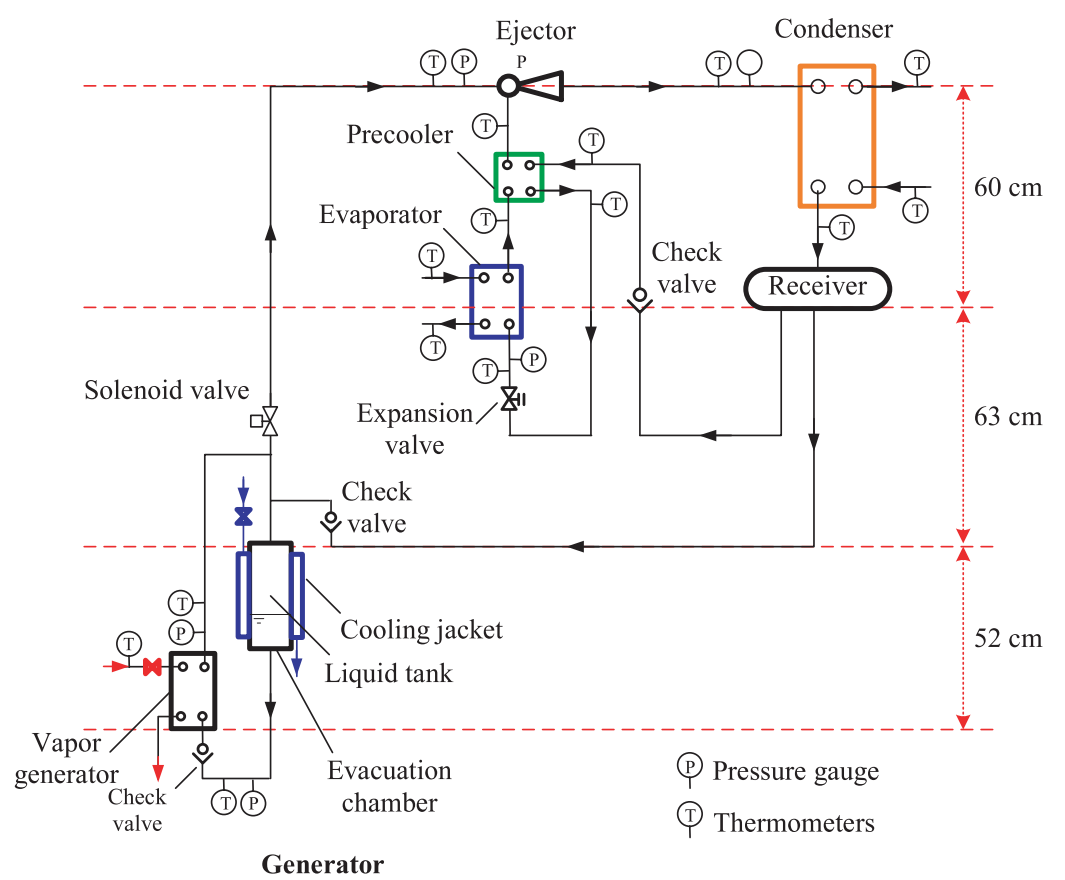

Fig. 5. Schematic description of experimental setup.

was used for data acquisition. The power consumption of the electrical heater was measured by a power-meter (TES) within $\pm 1.5 \%$ uncertainty. The water flow rates of the condenser, the evaporator, and the cooling of the MFG were measured with water flow meters within $\pm 4 \%$ uncertainty.

\section{Test results}

The performance of an ECS is evaluated with the coefficient of performance (COP), defined as the ratio of the cooling capacity at the evaporator to the thermal energy input at MFG. Two COP are defined and determined. The system COP at vapor discharge phase, $\mathrm{COP}_{\mathrm{o}}$, is defined as:

$\mathrm{COP}_{\mathrm{o}}=$

total cooling energy obtained at vapor discharge phase total heat input at vapor discharge phase

$=\frac{Q_{\mathrm{E}}}{Q_{\mathrm{G}}}=\frac{Q_{\mathrm{E}}}{Q_{\mathrm{C}}-Q_{\mathrm{E}}}$ where $Q_{\mathrm{E}}$ and $Q_{\mathrm{G}}$ are the total cooling energy and the total heat input of the ECS at vapor discharge phase, respectively; $Q_{\mathrm{C}}$ is the total rejected heat at vapor discharge phase. The cooling capacity and rejected heat are determined by an energy balance using the water flow rate and water temperature difference between the inlet and outlet.

$\mathrm{COP}_{t}$ is another COP taking into account the extra heat needed for liquid pump process in the MFG. The total system COP, $\mathrm{COP}_{t}$, is defined as:

$\mathrm{COP}_{\mathrm{t}}=$

Total cooling energy obtained at vapor discharge phase Total heat input per cycle

$=\frac{Q_{\mathrm{E}}}{Q_{\mathrm{h}}+Q_{\mathrm{G}}}=\frac{Q_{\mathrm{E}}}{Q_{\mathrm{h}}+Q_{\mathrm{C}}-Q_{\mathrm{E}}}$

where $Q_{\mathrm{h}}$ is the total heat input at pressurizing phase.

The uncertainties in measuring $\mathrm{COP}_{\mathrm{o}}$ and $\mathrm{COP}_{\mathrm{t}}$ are \pm 4.58 and $\pm 4.82 \%$, respectively.

Table 1

ECS design condition

\begin{tabular}{llllll}
\hline & Temperature $\left({ }^{\circ} \mathrm{C}\right)$ & Pressure $(\mathrm{kPa})$ & Flow rate $(\mathrm{kg} / \mathrm{s})$ & Heat transfer $(\mathrm{kW})$ & $\mathrm{COP}$ \\
\hline Generator & 90 & 538 & 0.0114 & 2.93 & 0.28 \\
Condenser & 36.7 & 119 & 0.0149 & 3.75 & \\
Evaporator & 8 & 40 & 0.0035 & 0.82 & \\
\hline
\end{tabular}


Table 2

Specifications of the ECS components

\begin{tabular}{ll}
\hline Components & Specification \\
\hline Nozzle A & Throat diameter $2.64 \mathrm{~mm}$, exit diameter $4.5 \mathrm{~mm}$ \\
Mixing chamber G & Constant area diameter $7.34 \mathrm{~mm}$; inlet converging angle $60^{\circ}$ \\
Condenser & Plate type, max. transfer rate $10 \mathrm{~kW}$; heat transfer area $4.09 \mathrm{~m}^{2}$ \\
Evaporator & Plate type, max. transfer rate $3.8 \mathrm{~kW}$; heat transfer area $0.72 \mathrm{~m}^{2}$ \\
Expansion valve & Hand needle valve, capacity $3.4 \mathrm{~kW}$ \\
Receiver & Stainless tank diameter $0.16 \mathrm{~m}$, height $0.32 \mathrm{~m}$ \\
\hline
\end{tabular}

The ECS/MFG was tested in ambient temperature around $25^{\circ} \mathrm{C}$. The cooling water was supplied from the city tap water at a temperature about $2-4{ }^{\circ} \mathrm{C}$ below the ambient temperature. A preliminary test for adjusting a suitable amount of filling refrigerant was done first.

Fig. 6 shows the typical half-cycle performance of the ECS/MFG. Each temperature line except the generator temperature was converted from the pressure measurement using R141b thermodynamic chart. At this half cycle, $\mathrm{COP}_{\mathrm{o}}$ is 0.211 and the average cooling capacity is $0.747 \mathrm{~kW}$ at average generating temperature $90{ }^{\circ} \mathrm{C}$, condensing temperature $35.5^{\circ} \mathrm{C}$ and evaporating temperature $7{ }^{\circ} \mathrm{C}$.

The system was started by introducing the hot steam into vapor generator that causes generator temperature to increase. In the pressurizing phase, the generator temperature was rapidly increased from 27 to $92^{\circ} \mathrm{C}$. When the temperature reached the designed state, the solenoid valve opened, allowed the motive steam, i.e. the primary flow, to flow into the ejector. The entrained flow was then actuated and produces cooling effect. This is also associated with a temporary evaporator temperature decreasing and then remaining constant around at $8{ }^{\circ} \mathrm{C}$. The time from the initially entraining flow to the desired evaporating temperature, $8{ }^{\circ} \mathrm{C}$, took approximately $40 \mathrm{~s}$. This time delay was due to the thermal inertia of the evaporator and the precooler etc. However, it can be compensated if two MFGs are collaterally operated.

As seen from Fig. 6, the vapor generating temperature as well as generator temperature varies about $5{ }^{\circ} \mathrm{C}$ at the vapor discharge phase. But this does not affect the evaporating temperature since the ECS operates at critical mode with double choking for primary and entrained flow.

After the vapor discharge phase, the depressurizing phase is triggered with the switching valve closing and then the pressure and the temperature of the MFG start to drop.
This phase is started by introducing cooling water into the cooling jacket. After the pressure drop to a low level, there then comes the retrieval of the working fluid and the process enters the liquid intake phase, where the temperature remained approximately constant.

Fig. 7 shows a typical continuous operation of the ECS/ MFG in half-cycle. In this operation, the $\mathrm{COP}_{\mathrm{o}}$ is 0.202 and the average cooling capacity is $0.733 \mathrm{~kW}$ at average generating temperature $90{ }^{\circ} \mathrm{C}$, condensing temperature $32.1{ }^{\circ} \mathrm{C}$ and evaporating temperature $6.8^{\circ} \mathrm{C}$. It is seen that the evaporating temperature is lower in the last two cycles. This is due to the temperature decrease of the city tap water during test. The test results have shown that the design of ECS/MFG is feasible.

Different test results at generating temperature $90{ }^{\circ} \mathrm{C}$ and various evaporating temperature are shown in Table 4 . The results of $\mathrm{COP}_{\mathrm{o}}$ for the present $\mathrm{ECS} / \mathrm{MFG}$ lie in the range 0.146-0.219 for different evaporating temperature. The average pressurizing time $t_{\mathrm{p}}$ is about $51 \mathrm{~s}$, the average time of vapor discharge phase $t_{\mathrm{v}}$ is $366 \mathrm{~s}$, and the average total time of depressurizing and liquid intake phases $t_{\mathrm{dp}}$ is $225 \mathrm{~s}$. Therefore, the average total time for pressurizing, depressurizing and liquid intake phases are $276 \mathrm{~s}$ which is shorter than the time required for cooling effect generation by $90 \mathrm{~s}$ at vapor discharge phase. This verifies that a continuous cooling is possible by regularly switching the two MFGs of an ECS/MFG. Table 4 also shows that the $\mathrm{COP}_{\mathrm{t}}$ lies in the range $0.125-0.183$ for different evaporating temperature. The difference between $\mathrm{COP}_{\mathrm{o}}$ and $\mathrm{COP}_{t}$ is due to the consideration of the energy required for the liquid pumping in $\mathrm{COP}_{\mathrm{t}}$. Actually, $\mathrm{COP}_{\mathrm{t}}$ can be further improved by decreasing the heat losses in the MFG. One of the heat losses is due to the amount of remaining liquid (dead liquid) in the liquid tank at the end of vapor discharge phase. This liquid is

Table 3

Specifications of the MFG components

\begin{tabular}{ll}
\hline Components & Specification \\
\hline Liquid tank & Stainless tank diameter $0.16 \mathrm{~m}$, height $0.32 \mathrm{~m} .0 .75 \mathrm{~kg}$ \\
Check valve & $7 / 8^{\prime \prime}$, gravity type, max. working pressure $4.15 \mathrm{MPa}, 0.2 \mathrm{~kg}$ \\
Connecting Tube & $7 / 8^{\prime \prime}$ copper tube, $1.4 \mathrm{~kg}$ \\
Cooling jacket & $\mathrm{PVC}$, heat transfer area $0.2 \mathrm{~m}^{2}$ \\
Vapor generator & Plate type, max. transfer rate $3.8 \mathrm{~kW} 2.47 \mathrm{~kg}$, heat transfer area $0.72 \mathrm{~m}^{2}$ \\
Solenoid valve & $3 / 8^{\prime \prime}$, max. working pressure $2.94 \mathrm{MPa}$; fluid temperature -40 to $125^{\circ} \mathrm{C}$ \\
\hline
\end{tabular}




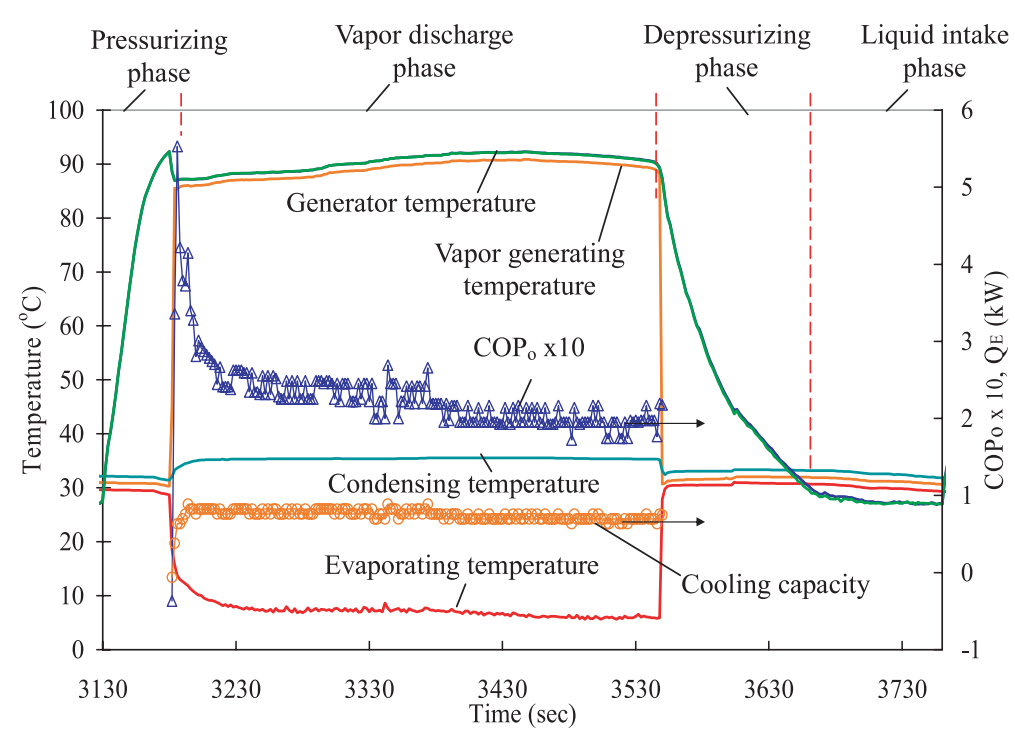

Fig. 6. Typical half cycle of ECS/MFG performance.

cooled first at the depressurizing and liquid intake phases and will need to be heated again at the pressurizing and vapor discharge phases. In our experiment, it is about $38-47 \%$ of the filling working fluid. In view of this fact, this dead liquid can be reduced in order to increase the $\mathrm{COP}_{\mathrm{t}}$ by improving the thermosyphon design of the liquid flowing to the vapor generator. The rate of liquid supply to liquid tank can be increased by increasing the height between the liquid tank and vapor generator. In the present experiment, no circulation problems were found.

The measured cooling capacity, $\mathrm{COP}_{\mathrm{o}}$, and $\mathrm{COP}_{\mathrm{t}}$ of the ECS/MFG at generating temperature $90{ }^{\circ} \mathrm{C}$ are shown in Fig. 8.

\section{Discussions and conclusion}

An ejector cooling system (ECS) that utilizes a multifunction generator (MFG) to eliminate the mechanical pump was designed and tested in the present study. The MFG serves as both a pump and a vapor generator. The test results have shown that the design of ECS/MFG is feasible and a continuous cooling is attainable by regularly switching the two MFGs of an ECS/MFG. Some important results from experiment are obtained and summarized as follows:

(1) The design of an ECS/MFG is feasible. A continuous operation for the generation of cooling effect can be

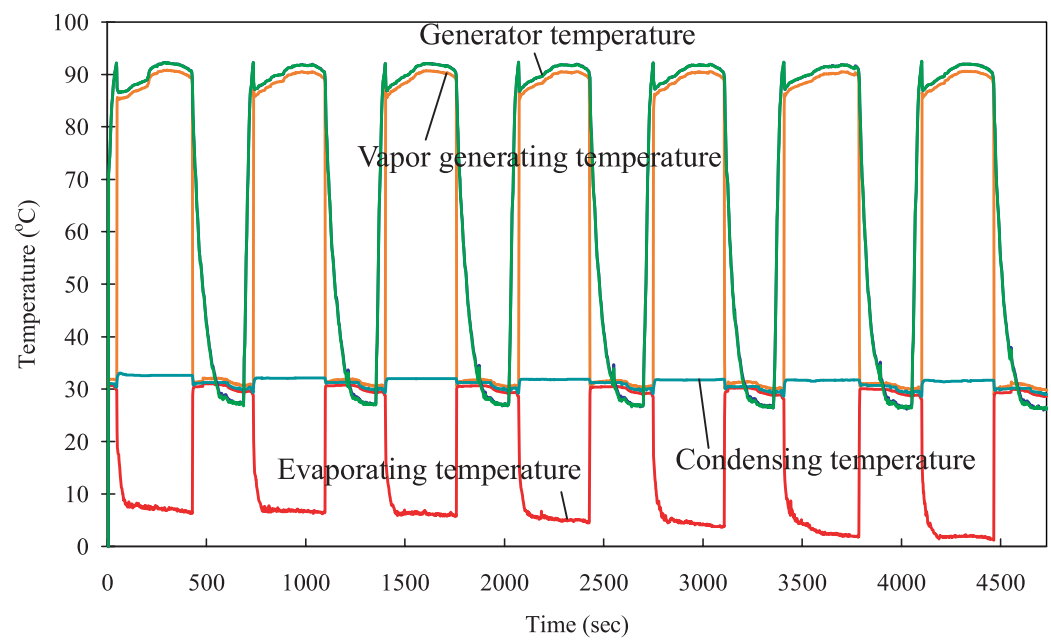

Fig. 7. Continuous operation of ECS/MFG in half-cycle. 
Table 4

Operating results at generating temperature $90{ }^{\circ} \mathrm{C}$

\begin{tabular}{lllllllll}
\hline No & $t_{\mathrm{p}}(\mathrm{s})$ & $t_{\mathrm{v}}(\mathrm{s})$ & $t_{\mathrm{dp}}(\mathrm{s})$ & $T_{\mathrm{C}}\left({ }^{\circ} \mathrm{C}\right)$ & $T_{\mathrm{E}}\left({ }^{\circ} \mathrm{C}\right)$ & $Q_{\mathrm{E}}(\mathrm{kW})$ & $\mathrm{COP}_{\mathrm{o}}$ & $\mathrm{COP}_{\mathrm{t}}$ \\
\hline 1 & 52 & 362 & 264 & 31.6 & 1.8 & 0.555 & 0.146 & 0.125 \\
2 & 50 & 382 & 260 & 31.7 & 2.5 & 0.574 & 0.155 & 0.133 \\
3 & 50 & 358 & 248 & 31.7 & 4.5 & 0.626 & 0.169 & 0.144 \\
4 & 52 & 384 & 212 & 35.4 & 5 & 0.642 & 0.184 & 0.157 \\
5 & 50 & 356 & 270 & 31.8 & 5.5 & 0.661 & 0.179 & 0.153 \\
6 & 50 & 358 & 262 & 32 & 6.2 & 0.664 & 0.191 & 0.161 \\
7 & 56 & 350 & 222 & 32.9 & 6.2 & 0.671 & 0.194 & 0.161 \\
8 & 54 & 354 & 210 & 35.3 & 6.2 & 0.687 & 0.198 & 0.165 \\
9 & 52 & 384 & 196 & 35.7 & 6.5 & 0.693 & 0.200 & 0.170 \\
10 & 50 & 360 & 250 & 32.1 & 6.8 & 0.733 & 0.202 & 0.172 \\
11 & 52 & 362 & 224 & 32.8 & 7 & 0.724 & 0.196 & 0.167 \\
12 & 52 & 376 & 198 & 34.9 & 7 & 0.701 & 0.200 & 0.169 \\
13 & 50 & 358 & 210 & 35.2 & 7 & 0.732 & 0.204 & 0.174 \\
14 & 50 & 370 & 206 & 35.5 & 7 & 0.747 & 0.211 & 0.180 \\
15 & 50 & 386 & 188 & 35 & 7.4 & 0.720 & 0.208 & 0.178 \\
16 & 52 & 344 & 202 & 35.6 & 7.5 & 0.747 & 0.215 & 0.180 \\
17 & 52 & 344 & 196 & 38 & 7.5 & 0.741 & 0.219 & 0.183 \\
18 & 54 & 354 & 260 & 32.8 & 7.7 & 0.779 & 0.211 \\
19 & 52 & 368 & 232 & 32.4 & 8.2 & 0.786 & 0.218 & 0.178 \\
20 & 42 & 402 & 190 & 36.9 & 9 & 0.677 & 0.189 & 0.185 \\
Average & 51 & 366 & 225 & & & & 0.165 \\
\hline
\end{tabular}

attainable. This machine can be very reliable since there is no moving part.

(2) $\mathrm{COP}_{\mathrm{o}}$ of the ECS/MFG is 0.218 and the average cooling capacity is $0.786 \mathrm{~kW}$ at generating temperature $90{ }^{\circ} \mathrm{C}$, condensing temperature $32.4^{\circ} \mathrm{C}$ and evaporating temperature $8.2^{\circ} \mathrm{C}$. $\mathrm{COP}_{\mathrm{t}}$ is 0.185 while taking into account the extra heat needed for liquid return to vapor generator. The $\mathrm{COP}_{\mathrm{o}}$ here is 0.218 which is lower than 0.54 , Huang et al. [1,2], at generator temperature $84{ }^{\circ} \mathrm{C}$, condensing temperature $28^{\circ} \mathrm{C}$, and evaporating temperature $8{ }^{\circ} \mathrm{C}$. According to the performance characteristic, for a given constant evaporator temperature, increasing the generator temperature resulted in worse COP, but the cycle could be operated at higher critical condenser pressure and would therefore be less susceptible to changing condenser conditions in practical applications. Due to the high heat sink temperatures during summer time in Taiwan, condensing temperature higher than $30^{\circ} \mathrm{C}$ is inevitable and this will sacrifice the performance of the system.

(3) The design of MFG in the present study shows that the time for vapor discharge phase is longer than the total time for the depressurizing, liquid intake, and pressurizing phases. This can assure the continuous operation

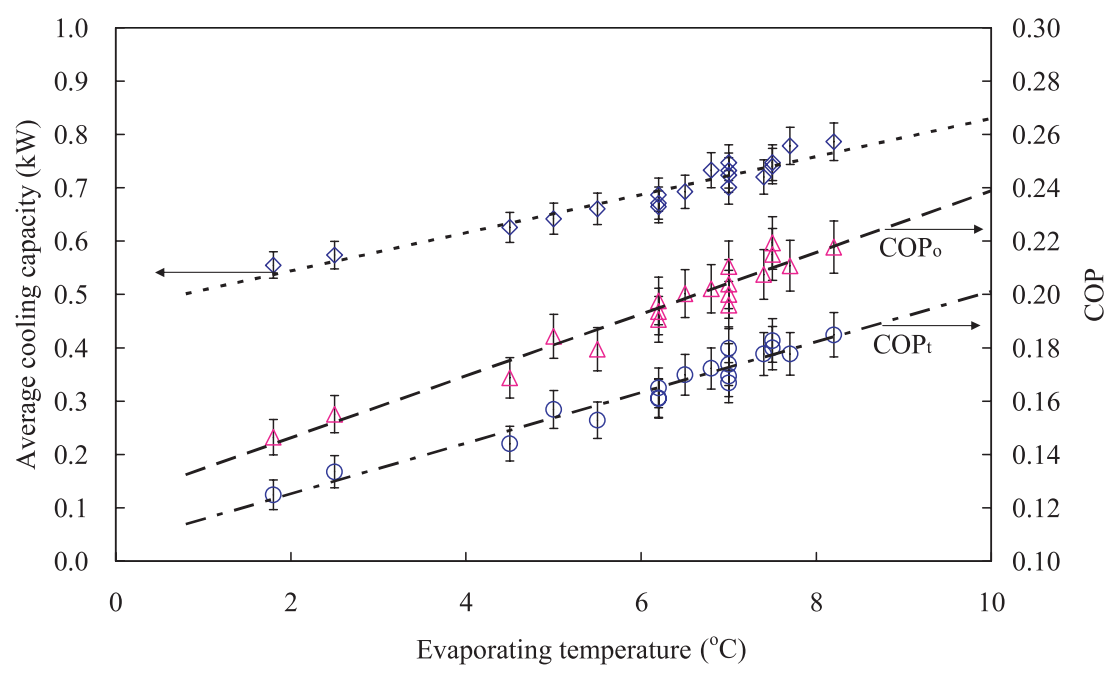

Fig. 8. Cooling capacity, $\mathrm{COP}_{\mathrm{o}}$ and $\mathrm{COP}_{\mathrm{t}}$ of $\mathrm{ECS} / \mathrm{MFG}$ at generating temperature $90{ }^{\circ} \mathrm{C}$ under critical mode. 
of an ECS/MFG using dual MFGs associated with a suitable switching device.

However, some more improvements still can be made in the future, including

(1) Increasing the thermosyphon effect for liquid return to the vapor generator during liquid intake phase by increasing the height between the liquid tank and the vapor generator. This will also reduce the operating time of the pressurizing phase and the energy consumption as well.

(2) Filling more working fluid so as to increase the operating time of the vapor discharge phase.

(3) Increasing the heat transfer area in the liquid tank in order to speed up the depressurizing phase.

(4) Reducing the thermal mass of the MFG design in order to speed up the response and reduce energy loss.

(5) Operating at optimal condition to have higher COP.

It may be emphasized that the present design of the $\mathrm{ECS} / \mathrm{MFG}$ is not optimal since the object of the present study is to show the feasibility of the ECS/MFG. Further research work, both experimental and theoretical, needs to be done to optimize the performance of the MFG and the ECS/MFG.

An ECS/MFG. with two MFGs is currently being designed and built, as shown in Fig. 9. This system will utilize automatic control to get a constant evaporating temperature. Better operating conditions will be tested to

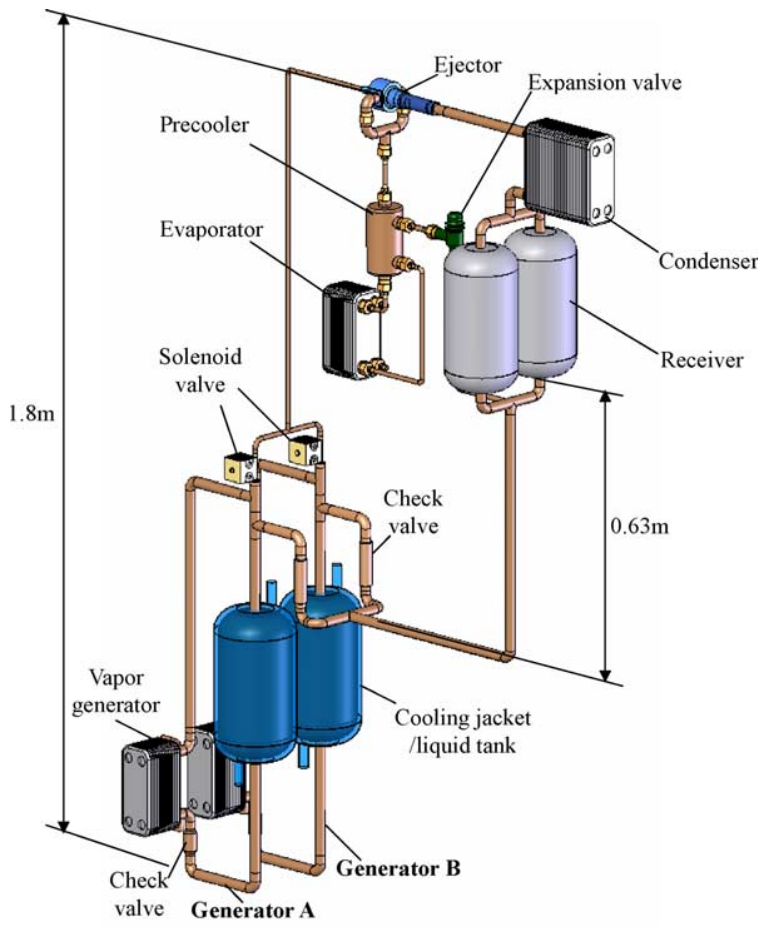

Fig. 9. Configuration of ECS/MFG with two MFGs. have higher COP as well. Thus, the system is purely heatoperated cycle.

\section{Acknowledgements}

The present study was supported by Energy Bureau, Ministry of Economic Affairs, Taiwan, ROC.

\section{References}

[1] B.J. Huang, J.M. Chang, Empirical correlation for ejector design, Int J Refrigeration 22 (1999) 379-388.

[2] B.J. Huang, J.M. Chang, C.P. Wang, V.A. Petrenko, A 1D analysis of ejector performance, Int J Refrigeration 22 (1999) 354-364.

[3] V.M. Nguyen, S.B. Riffat, P.S. Doherty, Development of a solar-powered passive ejector cooling system, Appl Therm Eng 21 (2001) 157-168.

[4] Y.W. Wong, K. Sumathy, Solar thermal water pumping systems: a review, Renewable Sustainable Energy Rev 3 (1999) 185-217.

[5] D.P. Rao, K.S. Rao, Solar water pump for lift irrigation, Solar Energy 18 (1976) 405-411.

[6] K. Sudhakar, M. Murali Krishna, D.P. Rao, Analysis and simulation of a solar water pump for lift irrigation, Solar Energy 24 (1979) 71-82.

[7] M.P. Sharma, G. Singh, A low lift solar water pump, Solar Energy 25 (1980) 273-278.

[8] R. Burton, A solar powered diaphragm pump, Solar Energy 31 (1983) 523-525.

[9] K. Sumathy, A. Venkatesh, V. Sriramulu, Thermodynamic analysis of a solar thermal water pump, Solar Energy 57 (1996) 155-161.

[10] A.A. Al-Haddad, E. Enaya, M.A. Fahim, Performance of thermodynamic water pump, Appl Therm Eng 16 (1996) 321-334.

[11] K. Sumathy, Experimental studies on a solar thermal water pump, Appl Therm Eng 19 (1999) 449-459.

[12] V.J. Sasin, L.X. Hoa, N.M. Savchenkova, N.T.B. Ngoc, Outlook at application of bi-phase pulsing contour with intermediate vessel, IV Minsk international seminar 'heat pipes, heat pumps, refrigerators', 2000, p. 42-49.

[13] Y.W. Wong, K. Sumathy, Thermodynamic analysis and optimization of a solar thermal water pump, Appl Thermal Eng 21 (2001) 613-627.

[14] V.J. Sasin, L.X. Hoa, N.M. Savchenkova, Outlook at application of bi-phase pulsing contour for heat supply and cooling systems, Proceedings of the 12th international heat pipe conference, Russia, 2002, pp. 448-453.

[15] J.L. Xu, X.Y. Huang, T.N. Wong, Study on heat driven pump. Part 1 -experimental measurements, Int J Heat Mass Transfer 46 (2003) 3329-3335.

[16] J.L. Xu, T.N. Wong, X.Y. Huang, Study on heat driven pump. Part 2-mathematical modeling, Int J Heat Mass Transfer 46 (2003) 3337-3347.

[17] D. Das, M. Ram Gopal, Studies on a metal hydride based solar water pump, Int J Hydrogen Energy 29 (2004) 103-112. 